\title{
Comparison of Soil Fungal Community Structure in Different Peanut Rotation Sequences Using Ribosomal Intergenic Spacer Analysis in Relation to Aflatoxin-Producing Fungi
}

\author{
H. Sudini, C. R. Arias, M. R. Liles, K. L. Bowen, and R. N. Huettel
}

First, fourth, and fifth authors: Department of Entomology and Plant Pathology; second author: Department of Fisheries and Allied Aquacultures, and third author: Department of Biological Sciences, Auburn University, Auburn, AL 36849.

Accepted for publication 24 August 2010.

\begin{abstract}
Sudini, H., Arias, C. R., Liles, M. R., Bowen, K. L., and Huettel, R. N. 2011. Comparison of soil fungal community structure in different peanut rotation sequences using ribosomal intergenic spacer analysis in relation to aflatoxin-producing fungi. Phytopathology 101:52-57.

The present study focuses on determining soil fungal community structure in different peanut-cropping sequences by using a highresolution DNA fingerprinting technique: ribosomal intergenic spacer analysis (RISA). This study was initiated to determine fungal community profiles in four peanut-cropping sequences (continuous peanut, 4 years of continuous bahiagrass followed by peanut, peanut-corn-cotton, and peanut-cotton rotations), with a special focus to evaluate whether the profiles under investigation may have also indicated microbial differences that could affect Aspergillus flavus populations. Results indicated 75\%

carried out using A. flavus-specific primers (FLA1 and FLA2) and also through quantitative estimation on A. flavus and A. parasiticus agar medium. Population levels of $A$. flavus in soil samples ranged from zero to $1.2 \times 10^{3} \mathrm{CFU} \mathrm{g}{ }^{-1}$ of soil (based on culturable methods); however, the fungus was not detected with A. flavus-specific primers. The minimum threshold limit at which these aflatoxin-producing fungi could be detected from the total soil genomic DNA was determined through artificial inoculation of samples with 10 -fold increases in concentrations. The results indicated that a minimum population density of $2.6 \times 10^{6} \mathrm{CFU} \mathrm{g}^{-1}$ of soil is required for PCR detection in our conditions. These results are useful in further determining the relative population levels of these fungi in peanut soils with other soil fungi. This is a new approach to understanding soil fungal communities and how they might change over time and under different rotation systems.
\end{abstract} similarities among fungal communities from the same cropping sequences as well as with similar times of sampling. Polymerase chain reaction (PCR)-based detection of A. flavus directly from these soils was
Additional keywords: aflatoxigenic fungi.

diversity (7). To arrive at a particular microbial community profile that would be beneficial to crop health, a long-term rotation or sequence of crops is desirable $(12,22,26)$. Once a soil suppressive to preharvest aflatoxin contamination is achieved through such long-term crop rotations, then it is possible to concentrate on microbial interactions that make the soil suppressive to A. flavus populations. Investigations in crop-fungus interactions that reduced the A. flavus populations and subsequent identification of microbial groups that helps to reduce the population levels of these aflatoxin-producing fungi in peanut soils will be of much use in devising novel strategies for reduced risk in peanut.

Over recent years, it has become possible to investigate soil microbial community structure using culture-independent techniques. These methods include DNA fingerprinting techniques such as denaturing gradient gel electrophoresis, terminal restriction fragment length polymorphism, length heterogeneity polymerase chain reaction (PCR), ribosomal intergenic spacer analysis (RISA), cloning, and sequencing in addition to conventional microbial estimation through quantitative methods $(6,21,27)$. These techniques provide rapid, lucid, reliable, and highly reproducible results for determining soil fungal community structures. Of these molecular techniques, RISA provides greater resolution and analysis of soil microbial diversity than other techniques (6). Use of RISA in determining fungal diversity in soils exploits the length polymorphism of the nuclear ribosomal DNA (rDNA) region that contains two internal transcribed spacers (ITSs) and the 5.8S rRNA gene (ITS1-5.8S-ITS2) (24). A better insight into these community structures with an efficient molecular technique such as RISA, with emphasis on aflatoxin-producing fungi, may 
provide a better understanding and subsequent management approaches to the aflatoxin problem.

In this study, the fungal communities from cropping sequences of peanut crops (P-P-P-P), 4 years of continuous bahiagrass followed by peanut (B-B-B-B-P), peanut-corn-cotton (P-Cn-Ct-P), and peanut-cotton (P-Ct-P-Ct) were compared. In addition to total fungal communities, the specific identification of $A$. flavus aflatoxin-producing fungi was addressed. Detection of $A$. flavus populations in soils was carried out using specific primers and through quantitative estimation. Quantification of minimum population loads of aflatoxin-producing fungi in soils, to determine levels needed for analysis of soil genomic DNA through molecular methods, was conducted.

\section{MATERIALS AND METHODS}

Field site history and description. The experimental site was located at the Wiregrass Research and Extension Center, Headland, AL. The site was established in 1988 with an objective of managing peanut diseases such as early leaf spot, late leaf spot, southern stem rot, and peanut root knot diseases (11). There are 34 peanut-cropping sequences at this site, of which four were selected for this study: P-P-P-P; B-B-B-B-P, a 5-year sequence that started most recently in 2003; Ct-P-Ct-P; and P-Cn-Ct-P (Table 1). The soil is Dothan fine sandy-loam (fine-loamy, siliceous, thermic Plinthic Palendults) type ( $<1 \%$ organic matter). The crops were supplemented with side-roll irrigation system as needed. The plots were arranged in a randomized complete block design with four replications.

Soil sampling. For each sample, five soil cores were collected from the pegging zone (up to 10-cm depth) during 2006, 2007, and 2008 from each plot, bulked, and mixed for a representative sample. Samples were collected three times: early season (June), midseason (August), and at peanut harvest (October). The samples were processed within $24 \mathrm{~h}$ for total soil genomic-DNA extraction and preserved genomic material was stored at $-20^{\circ} \mathrm{C}$ for further downstream applications. The samples collected at the time of harvest were also subjected to enumeration of A. flavusgroup populations as well as determining the minimum threshold population limit of the A. flavus group of fungi at which they are detectable in soils.

DNA extraction and quantification. Total genomic DNA was extracted from $10 \mathrm{~g}$ of each soil sample using the Power Mac Soil kit from MoBio (MoBio Laboratories Inc., Carlsbad, CA) following the manufacturer's instructions. Extracted DNA quality (260/280 ratio) and quantity was assessed by Nano Drop Spectrophotometer (Thermo Scientific). DNA dilutions were carried out

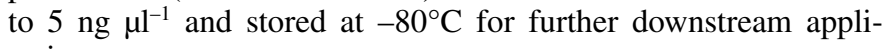
cations.

Fungal community fingerprinting by RISA. The length heterogeneity of the ITS1-5.8S-ITS2 region was exploited to characterize the fungal community. The primers used to amplify this region represent consensus sequences found at the $3^{\prime}$ end of the $18 \mathrm{~S}$ genes in fungi (primer 2234C, 5'-GTTTCCGTAGGTGAACCTGC-3') and at the $5^{\prime}$ end of the $28 \mathrm{~S}$ genes (primer 3126T, 5'-ATATGCTTAAGTTCAGCGGGT-3') (24). The reverse primer was labeled with IRD700 fluorochrome from Li-Cor (Lincoln, NE) at the $5^{\prime}$ end. Reaction mixtures $(50 \mu \mathrm{l})$ for PCR contained $5 \mu$ of $10 \times$ dilution buffer $(20 \mathrm{mM}$ Tris-HCl [pH 7.5], $100 \mathrm{mM} \mathrm{KCL}, 15 \mathrm{mM} \mathrm{MgCl} 2,1 \mathrm{mM}$ dithiothreitol, $0.1 \mathrm{mM}$
EDTA, 0.5\% Tween 20 [vol/vol], 0.5\% Nonidet P40 [vol/vol], and $50 \%$ glycerol [ $\mathrm{vol} / \mathrm{vol}]), 2 \mu \mathrm{l}$ of $10 \mathrm{mM}$ dNTPs, $2 \mu \mathrm{l}$ of $10 \mu \mathrm{M}$ primer $2234 \mathrm{C}, 1 \mu \mathrm{l}$ of $10 \mu \mathrm{M}$ primer $3126 \mathrm{~T}, 10 \mu \mathrm{l}$ of $1 \mu \mathrm{M} 2234 \mathrm{C}$ primer labeled with IRD700 fluorochrome from Li-Cor at the 5' end, $0.2 \mu \mathrm{l}$ of Taq polymerase (Promega Corp., Madison, WI), $10 \mu \mathrm{l}$ of $25 \mu \mathrm{M} \mathrm{MgCl}_{2}$, and $20 \mu \mathrm{l}$ of template DNA (100 ng). PCR amplification was carried out in a Peltier Thermal Cycler (PTC200, MJ Research) after a hot start at $94^{\circ} \mathrm{C}$ for $3 \mathrm{~min}$; followed by 30 cycles consisting of $94^{\circ} \mathrm{C}$ for $45 \mathrm{~s}, 55^{\circ} \mathrm{C}$ for $1 \mathrm{~min}$, and $68^{\circ} \mathrm{C}$ for $2 \mathrm{~min}$; and final extension for $7 \mathrm{~min}$ at $68^{\circ} \mathrm{C}$. Polyacrylamide gels were then prepared by mixing $30 \mathrm{ml}$ of $5.5 \%$ Li-Cor polyacrylamide (KB plus-Li-Cor), $200 \mu \mathrm{l}$ of $10 \%$ ammonium persulfate, and $20 \mu \mathrm{l}$ of $\mathrm{N}, \mathrm{N}, \mathrm{N}^{\prime} \mathrm{N}^{\prime}$-tetramethylethylenediamine. The PCR product $(5 \mu \mathrm{l})$ was then transferred to new tubes and, to this, $2.5 \mu$ of stop buffer (Li-Cor, Blue Stop Solution) was added. The contents were thoroughly mixed and denatured at $98^{\circ} \mathrm{C}$ for $5 \mathrm{~min}$ before loading onto the polyacrylamide gel. The denatured PCR products $(0.6$ to $0.8 \mu \mathrm{l})$ were electrophoresed on the NEN Global Edition IR2 DNA Analyzer (Li-Cor) under denaturing conditions for $8 \mathrm{~h}$ at 1,500 $\mathrm{V}$ following the manufacturer's instructions.

The RISA gel images were analyzed by the BIONUMERICS V. 5.0 (Applied Maths, TX) software program. Levels of similarity between fingerprints were calculated with the Pearson productmoment correlation coefficient $(r)$ after the banding patterns were subjected to conversion, normalization, and background subtraction with mathematical algorithms. The program used binary data based on the presence or absence of particular band in the fingerprint profile pairs being compared. The dendrogram was constructed by using unweighted pair-group method with arithmetic mean. The multidimensional scaling analysis (MDSA) tool in BioNumerics was used to evaluate the similarities or dissimilarities between soil fungal communities. Cluster analysis was performed with the unweighted pair-group method using average linkages to determine the relatedness among the fungal communities of different peanut-cropping sequences (1).

Enumeration and determination of minimum threshold population of $A$. flavus in soils. Initially, the soil population levels of $A$. flavus and $A$. parasiticus were enumerated on $A$. flavus and A. parasiticus agar (AFPA) according to Pitt et al. (23). Soil samples with no traces of A. flavus-group fungi, as determined by plating on AFPA, were selected for this experiment. These A. flavus-free soil samples were augmented with $A$. flavus spore suspensions at different concentrations ranging from $2 \times$ $10^{4}$ to $2 \times 10^{9} \mathrm{CFU} \mathrm{ml}{ }^{-1}$. Six soil samples $(10 \mathrm{~g}$ each) were weighed and $5 \mathrm{ml}$ of each spore concentration was added to individual soil samples in order to achieve A. flavus concentrations ranging from $2 \times 10^{3}$ to $2 \times 10^{8} \mathrm{CFU} \mathrm{g}^{-1}$. The total genomic DNA was extracted immediately from these samples using the Power Mac Soil kit from MoBio following the manufacturer's instructions. DNA was purified using protocol suggested by M. R. Liles (personal communication) for the determination of the minimum threshold level for A. flavus detection directly from the soil.

PCR-based detection for A. flavus in soil. The purified total soil genomic DNA was PCR amplified using the $A$. flavus-specific primers FLA1 (5'-GTAGGGTTCCTAGCGAGCC-3') and FLA2 (5'-GGAAAAAGATTGATTTGCGTTC-3') (9). The concentration of $A$. flavus spore suspension that was added to the soil at which the fungal pathogen was detectable through PCR using $A$. flavus-specific primers was determined sequentially by increasing

TABLE 1. Crops grown in sampled rotations in each study year at the study site at the Wiregrass Research and Extension Center, Headland, AL

\begin{tabular}{|c|c|c|c|c|}
\hline Crop rotation & 2005 & 2006 & 2007 & 2008 \\
\hline Continuous peanut (P-P-P-P) & Peanut & Peanut & Peanut & Peanut \\
\hline Bahiagrass-peanut (B-B-B-B-P) & Bahiagrass & Bahiagrass & Peanut & Bahiagrass \\
\hline Peanut-cotton (Ct-P-Ct-P) & Cotton & Peanut & Cotton & Peanut \\
\hline Peanut-corn-cotton (P-Cn-Ct-P) & Peanut & Corn & Cotton & Peanut \\
\hline
\end{tabular}


or decreasing the spore concentration as needed. PCR reactions were performed in the Peltier Thermal Cycler (PTC-200; MJ Research). The PCR amplification protocol for A. flavus detection was as follows: 1 cycle of $5 \mathrm{~min}$ at $95^{\circ} \mathrm{C}$; followed by 26 cycles of $30 \mathrm{~s}$ at $95^{\circ} \mathrm{C}, 30 \mathrm{~s}$ at $58^{\circ} \mathrm{C}$, and $45 \mathrm{~s}$ at $72^{\circ} \mathrm{C}$; and a final extension of $5 \mathrm{~min}$ at $72^{\circ} \mathrm{C}$. The PCR products were run on $1 \%$ agarose gel electrophoresis and subjected to ethidium bromide staining.

A colored by sampling time

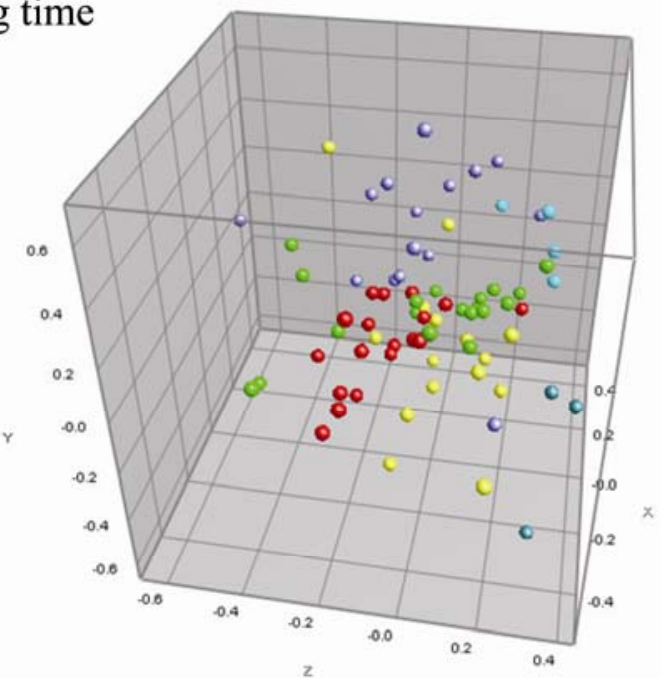

June '06

August '06

October '06
June '07

August '07

October '07

\section{B colored by crop rotation}

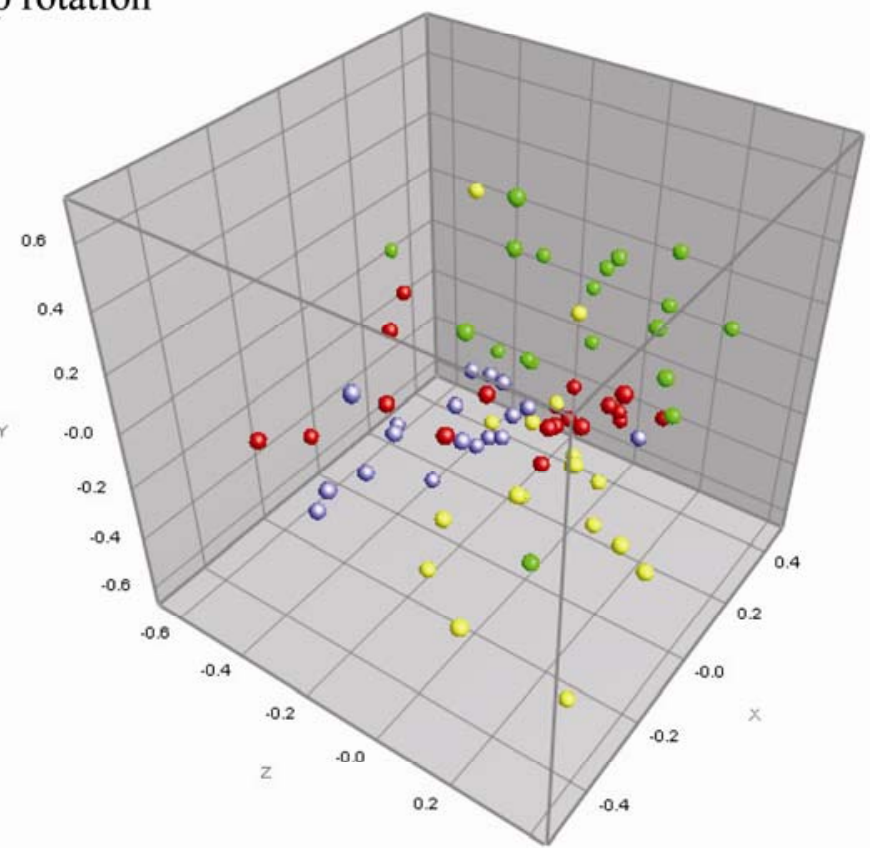

\section{Continuous Peanut}

\section{Cotton-Peanut}

4 yrs Continuous Bahiagrass + Peanuts

Peanut-Cotton-Corn

Fig. 1. Multidimensional scaling analysis of soil fungal communities. A, Colored by sampling time: June 2006. June 2007. August 2006. August 2007. October 2006. and October 2007. B, Colored by crop rotation: continuous peanut, cotton-peanut, 4 years of continuous bahiagrass + peanut, and peanut-cotton-corn. 
Statistical analysis. Data were analyzed using analysis of variance (SAS Institute, Cary, NC). The PROC GLM procedure was used to separate the mean population levels of $A$. flavus over 3 years.

\section{RESULTS}

RISA analysis of fungal communities. Fungal RISA profiles showed similarities among communities from replicate plots of the same crop rotation (data not shown). In general, similarities of 55 to $75 \%$ were observed among plots of different cropping sequences in 2006 to 2007. Common bands were observed among all samples regardless of sampling time and cropping sequence. RISA banding patterns in P-P-P-P indicated that there was $\approx 75 \%$ similarity in these plots sampled in October 2006. In the case of B-B-B-B-P, 70\% similarity was observed in plots sampled during June 2006. The banding patterns from these same plots showed a marginal increase in similarity when sampled during October 2006 (75\% similarity). In Ct-P-Ct-P, for the plots sampled in August 2007, $\approx 80 \%$ similarity was noticed, whereas the plots sampled in August and October 2006 had $\approx 75 \%$. On the other hand, P-Cn-Ct-P rotation plots sampled in August 2006 clustered at $85 \%$ similarity and at $\approx 80 \%$ when sampled during August 2007.

MDSA of RISA community profiles revealed that fungal communities showed greater similarity based on time of sampling than based on cropping sequence (Fig. 1A). This can be clearly seen in the tighter grouping of the August 2006 observations and few outliers in the case of other groupings. Lesser similarities were observed with respect to fungal composition cropping sequence (Fig. 1B), indicating that the impact of cropping sequence on soil fungal diversity is minimal.

Enumeration and PCR-based detection of soil A. flavus. A. flavus soil populations, determined at the time of harvest from each cropping sequence, indicated a marginal increase in population levels of $A$. flavus within cropping sequences of P-P-P-P and in Ct-P-Ct-P rotation. The population levels in these cropping

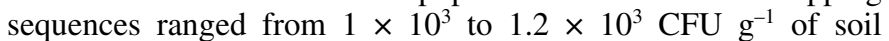
through 2006 to 2008. Populations remained constant in the P$\mathrm{Cn}-\mathrm{Ct}-\mathrm{P}$ rotation through 2006 to 2008. A substantial decline in soil A. flavus populations was observed in the B-B-B-B-P cropping sequence in 2006 to $2008\left(0.7 \times 10^{3}\right.$ to $0.2 \times 10^{3} \mathrm{CFU} \mathrm{g}^{-1}$ of soil) (Table 2).

Comparisons of mean A. flavus population levels over 3 years indicated that, among the four cropping sequences, A. flavus populations were significantly less in soils from B-B-B-B-P $\left(0.2 \times 10^{3} \mathrm{CFU} \mathrm{^{-1 }}\right.$ of soil) compared with other treatments. The population levels in P-P-P-P, Ct-P-Ct-P, and P-Cn-Ct-P sequences were $1.2 \times 10^{3}, 1.2 \times 10^{3}$, and $1.0 \times 10^{3} \mathrm{CFU} \mathrm{g}^{-1}$ of soil, respectively; and no significant differences were observed among these three cropping sequences (Table 2). The minimum threshold limit at which A. flavus can be detected in peanut soils directly from

TABLE 2. Population levels of Aspergillus flavus group in soils from different peanut cropping sequences

\begin{tabular}{lcccc}
\hline & \multicolumn{4}{c}{$\begin{array}{c}\text { Soil A. flavus population at harvest } \\
\left(\times 10^{3} \mathrm{CFU} \mathrm{g}^{-1} \text { of soil }\right)\end{array}$} \\
\cline { 2 - 5 } Rotation & 2006 & 2007 & 2008 & Mean $^{\mathrm{w}}$ \\
\hline Continuous peanut & 1.0 & 1.0 & 1.2 & $1.1 \mathrm{a}$ \\
Bahiagrass-peanut & $0.7^{\mathrm{x}}$ & 0.0 & $0.2^{\mathrm{x}}$ & $0.3 \mathrm{~b}$ \\
Peanut-cotton & 1.0 & $1.1^{\mathrm{y}}$ & 1.2 & $1.1 \mathrm{a}$ \\
Peanut-corn-cotton & $1.0^{\mathrm{z}}$ & $0.8^{\mathrm{y}}$ & 1.0 & $0.9 \mathrm{a}$ \\
\hline
\end{tabular}

${ }^{w}$ Mean over 3 years; means followed by the same letter are not significantly different and the treatment means were separated using least significant difference $(P=0.01)$.

${ }^{x}$ Plots were planted to bahiagrass.

y Plots were planted to cotton.

z Plots were planted to corn. soil genomic DNA with A. flavus-specific primers was found to be $2.6 \times 10^{6} \mathrm{CFU} \mathrm{g}^{-1}$ (Fig. 2).

\section{DISCUSSION}

Fungal RISA profiles with common bands in all cropping sequences in the present study may be attributed to the presence of common saprophytes in these soils. However, the phylogenies of these saprophytes in soils were not determined. The effect of particular plant species on the selection of resident soil microbial communities is well documented $(7,8,10,29)$. This influence is due to differential root exudates into the rhizosphere. For this reason, the microbial diversity of a rhizosphere and nonrhizosphere soil differ greatly (15). In our study, however, sampling time had a more profound effect on similarities of these communities compared with crop. One probable explanation for this is that the experimental site is in a long-term rotation, and cropmanagement practices such as tillage, irrigation, and soil nutrient application year after year might be masking the effect of plant type on the soil microbial communities (5). Another reason could be that, at each sampling time, at least two of the four rotations had the same crop (e.g., peanut in two treatments in 2006). MDSA also revealed that there was no selection of fungal communities based on plant type because this analysis enables grouping of fungal communities based on presence or absence of bands and their intensity.

Overall, our results suggest that, though different RISA groups were detected based on sampling times and cropping sequences with peanut, a specific fungal community associated with these sequences could not be confirmed concretely. To ascertain the phylogeny of these fungal communities in different cropping sequences, 18S rDNA sequencing of fungi from the soil of these cropping sequences is an alternative for better understanding of the fungal communities associated with these crops in a peanut ecosystem.

Our study on the detection of aflatoxin-producing fungal populations in soils revealed that PCR-based methods using $A$.

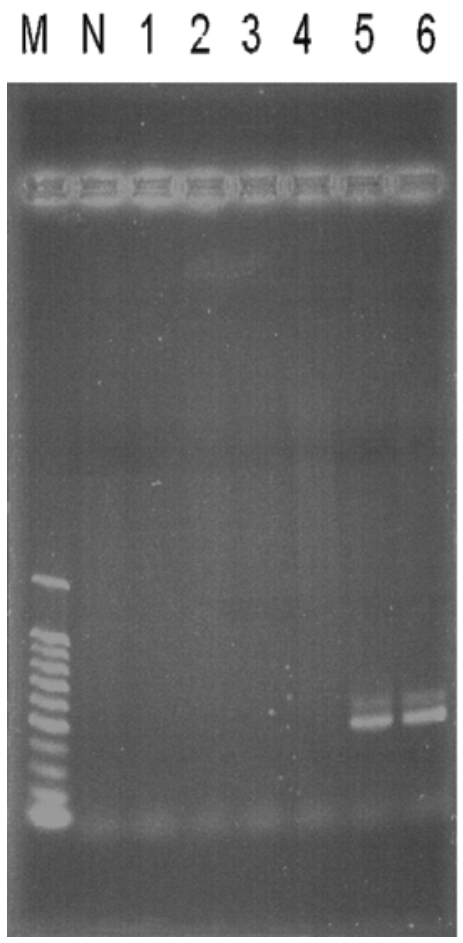

Fig. 2. Polymerase chain reaction with Aspergillus flavus-specific primers. Lane $\mathrm{M}=100$-bp marker, lane $\mathrm{N}=$ negative control, and lanes 1 to 6 are soil samples inoculated with Aspergillus flavus spores at $10^{2}$ to $10^{7} \mathrm{CFU} / \mathrm{g}$ of soil. 
flavus-specific primers could not detect these fungi even at a concentration of $10^{3} \mathrm{CFU} \mathrm{g}{ }^{-1}$ soil. There are several possible reasons for this. One reason might be the presence of high amounts of PCR inhibitors in the soil metagenomic DNA such as humic acids (31). Separation of humic substances from a DNA sample is always a critical phase because both of these are acid macromolecules. Another reason could be that the DNA extraction method used in the present study might affect the yields of DNA from A. flavus and, subsequently, the obtained DNA might be less than the primer's sensitivity limits. However, other extraction methods that might yield more A. flavus DNA can be more specific in identifying these populations from soils. Further studies on how to improve PCR-based detection of A. flavus from soil would be beneficial.

Soil enumeration studies indicated that using bahiagrass in rotation with peanut resulted in lower A. flavus population levels compared with other cropping sequences. Though we did not dig deeper in our study as to why bahiagrass rotations did not favor the A. flavus populations, earlier reports indicated that sod-based rotations, including bahiagrass, improved soil health parameters by improving soil water infiltration rates, allowing greater nutrient uptake, increasing earthworm population densities, increasing the abundance of beneficial microorganisms, and, ultimately, increasing organic matter content $(16-18,20)$. Bahiagrass rotations might have contributed to soil organic matter at our study site, thereby increasing the antagonistic microflora and causing significant reductions in A. flavus population levels. In addition, in bahiagrass rotations in our study, more bands were observed in fingerprinting profiles (data not shown), indicating that an increase in soil microbial diversity is another contributing factor in lowering the A. flavus populations.

High population levels of A. flavus in P-P-P-P, Ct-P-Ct-P, and $\mathrm{P}-\mathrm{Cn}-\mathrm{Ct}-\mathrm{P}$ rotations compared with the rotation that included bahiagrass might be attributed to the continuous availability of host crops that favor multiplication of these fungi. However, if bahiagrass does increase organic matter, then the soil would hold moisture longer and A. flavus might not be as competitive among all other microbes. However, this speculation is in contrast to observations by Zablotowicz et al. (30), who reported that higher organic matter content in soils favors higher populations of $A$. flavus, though it is unknown whether the toxigenic and atoxigenic strains are higher in numbers. Population levels of A. flavus, A. parasiticus, A. terreus, A. nomius, A. tamari, A. niger, and A. fumigatus are reported to be high among common soil inhabitants of soils with peanut, corn, and cotton cultivation $(3,13)$, and our results are similar. On the other hand, we observed that the B-BB-B-P rotation had significantly lower A. flavus population levels than the other rotation sequences we studied. B-B-B-B-P in the present study might have improved the beneficial microflora through addition of soil organic matter, thus reducing the soil resident A. flavus population levels. Though our efforts are confined to understanding the comparative fingerprinting of fungal communities in different peanut long-term rotations, further studies are needed to better understand the interactions among various microbiotas and how they influence, specifically, the A. flavus group of fungi.

\section{ACKNOWLEDGMENTS}

We thank O. Olivares-Fuster of Fisheries and Allied Aquacultures department for his assistance in this project.

\section{LITERATURE CITED}

1. Arias, C. R., Welker, T. L., Shoemaker, C. A., Abernathy, J. W., and Klesius, P. H. 2004. Genetic fingerprinting of Flavobacterium columnare isolates from cultured fish. J. Appl. Microbiol. 97:421-428.

2. Bowen, K. L., Hagan, A. K., and Weeks, J. R. 1996. Soil-borne pests of peanut in growers' fields with different cropping histories in Alabama.
Peanut Sci. 23:36-42.

3. Cotty, P. J. 1997. Aflatoxin-producing potential of communities of Aspergillus section Flavi from cotton producing areas in the United States. Mycol. Res. 101:698-704.

4. Doran, J. W., Sarrantonio, M., and Liebig, M. A. 1996. Soil health and sustainability. Adv. Agron. 56:2-54.

5. Drinkwater, L. E., Wagoner, P., and Sarrantonio, M. 1998. Legume-based cropping systems have reduced carbon and nitrogen losses. Nature 396:262-265.

6. Fisher, M. M., and Triplett, E. W. 1999. Automated approach for ribosomal intergenic spacer analysis of microbial diversity and its application to fresh water bacterial communities. Appl. Environ. Microbiol. 65:4630-4636.

7. Garbeva, P., Van Elsas, J. D., and Van Veen, J. A. 2008. Rhizosphere microbial community and its response to plant species and soil history. Plant Soil 302:19-32.

8. Garland, J. L. 1996. Patterns of potential C source utilization by rhizosphere communities. Soil Biol. Biochem. 28:223-230.

9. Gonzalez-Salgado, A., Gonzalez-Jaen, T., Vazquez, C., and Patino, B. 2008. Highly sensitive PCR-based detection method specific for Aspergillus flavus in wheat flour. Food Addit. Contam. 25:1-7.

10. Grayston, S. J., Wang, S., Campbell, C. D., and Edwards, A. C. 1998. Selective influence of plant species on microbial diversity in the rhizosphere. Soil Biol. Biochem. 30:369-378.

11. Hagan, A. K., Campbell, L. H., Weeks, J. R., Rivas-Davila, M. E., and Gamble, B. 2003. Impact of bahiagrass, cotton, and corn cropping frequency on the severity of diseases of peanut. Pages 46-58 in: Proc. Sod Based Cropping Syst. Conf. North Florida Research and Education Center-Quincy, University of Florida.

12. Hoekstra, O. 1989. Results of twenty-four years of crop rotation research at 'De Schreef' experimental site. Pages 37-43 in: Effects of Crop Rotation on Potato Production in the Temperate Zones. J. Vos, C. D. Van Loon, and G. J. Bollen, eds. Kluwer Academic Publishers, Dordrecht, The Netherlands.

13. Horn, B. W., Greene, R. L., and Dorner, J. W. 1995. Effect of corn and peanut cultivation on soil populations of Aspergillus flavus and A. parasiticus in southwestern Georgia. Appl. Environ. Microbiol. 61:24722475.

14. IARC. 1993. Some Naturally Occurring Substances: Food Items and Constituents, Heterocyclic Aromatic Amines and Mycotoxins. Monogr. 56. International Agency for Research on Cancer, France.

15. Ibekwe, A. M., and Kennedy, A. C. 1998. Phospholipid fatty acid profiles and carbon utilization patterns for analysis of microbial community structure under field and greenhouse conditions. FEMS Microbiol. Ecol. 26:151-163.

16. Katsvairo, T. W., Wright, D. L., Marois, J. J., Hartzog, D. L., Balkcom, K. B., Wiatrak, P. P., and Rich, J. R. 2007. Performance of peanut and cotton in a bahiagrass cropping system. Agron. J. 99:1245-1251.

17. Katsvairo, T. W., Wright, D. L., Marois, J. J., Hartzog, D. L., Rich, J. R., and Wiatrak, P. P. 2007. Cotton roots, earthworms and infiltration characteristics in sod/livestock peanut/cotton cropping systems. Agron. J. 99:390-398.

18. Katsvairo, T. W., Wright, D. L., Marois, J. J., and Rich, J. R. 2007. Transition from conventional farming to organic farming using bahiagrass. J. Sci. Food Agric. 87:2751-2756.

19. Lisker, N., Michaeli, R., and Frank, Z. R. 1993. Mycotoxigenic potential of Aspergillus flavus strains isolated from groundnuts growing in Israel. Mycopathologia 122:177-183.

20. Long, F. L., and Elkins, C. B. 1983. The influence of roots on nutrient leaching and uptake. Pages 335-352 in: Nutrient Cycling in Agricultural Ecosystems. Spec. Publ. 23. R. T. Lowrance, ed. College of Agricultural Experiment Stations, University of Georgia, Athens.

21. Muyzer, G., Waal, E. C. D., and Uitterlinden, A. G. 1993. Profiling of complex microbial populations by denaturing gradient gel electrophoresis analysis of polymerase chain reaction-amplified genes coding for $16 \mathrm{~S}$ rRNA. Appl. Environ. Microbiol. 59:695-700.

22. Peters, R. D., Sturz, A. V., Carter, M. R., and Sanderson, J. B. 2003. Developing disease-suppressive soils through crop rotations and tillage management practices. Soil Tillage Res. 72:181-192.

23. Pitt, J. I., Hocking, A. D., and Glenn, D. R. 1983. An improved medium for detection of Aspergillus flavus and A. parasiticus. J. Appl. Bacteriol. 54:109-114.

24. Ranjard, L., Poly, F., Lata, J. C., Mougel, C., Thioulouse, J., and Nazaret, S. 2001. Characterization of bacterial and fungal soil communities by automated ribosomal intergenic spacer analysis fingerprintings: Biological and methodological variability. Appl. Environ. Microbiol. 67:4479-4487.

25. Schroeder, H. W., and Boller, R. A. 1973. Aflatoxin production of species and strains of the Aspergillus flavus group isolated from field crops. Appl. Microbiol. 25:885-889. 
26. Specht, L. P., and Leach, S. S. 1987. Effects of crop rotation on Rhizoctonia disease of white potato. Plant Dis. 71:433-437.

27. Tiedje, J. M., Asuming-Brempong, S., Nusslein, K., Marsh, T. L., and Flynn, S. J. 1999. Opening the black box of soil microbial diversity. Appl. Soil Ecol. 13:109-122.

28. WHO. 1979. Environmental Health Criteria. 11. Mycotoxins. World Health Organization, Geneva.

29. Wieland, G., Neumann, R., and Backhaus, H. 2001. Variation of microbial communities in soil, rhizosphere and rhizoplane in response to crop species, soil type, and crop development. Appl. Environ. Microbiol. 67:5849-5854

30. Zablotowicz, R. M., Abbas, H. K., and Locke, M. A. 2007. Population ecology of Aspergillus flavus associated with Mississippi delta soils. Food Addit. Contam. 24:1102-1108.

31. Zhou, J., Bruns, M. A., and Tiedje, J. M. 1996. DNA recovery from soils of diverse composition. Appl. Environ. Microbiol. 62:316-322. 